\title{
Jejunal manometry in distal subacute mechanical obstruction: significance of prolonged simultaneous contractions
}

\author{
MICHAEL CAMILLERI \\ From the Gastroenterology Division, Mayo Clinic and Mayo Foundation, Rochester, MN, USA
}

SUMmary The aim of this study is to assess the value of jejunal manometry in the diagnosis of subacute mechanical obstruction distal to the proximal small bowel. In a retrospective review of 850 manometric tracings carried out in patients with unexplained nausea, vomiting, abdominal pain or altered bowel movements, 16 tracings were identified with features suggestive of mechanical obstruction: prolonged simultaneous contractions (PC) and postprandial clustered contractions (CC). Three patients had CC lasting less than 20 minutes: none proved to have mechanical obstruction. Among seven patients with CC lasting more than 30 minutes, three had proven mechanical obstruction, one probable adhesion obstruction, and in three no obstruction was found. All three patients with PC and three with mixed PC and CC had mechanical obstruction. The obstructed intestine manifests a variety of pressure profiles in the proximal jejunum: $\mathrm{PC}, \mathrm{CC}$, or mixed patterns. Prolonged simultaneous contractions are suggestive of distal subacute bowel obstruction; CC lasting over 30 minutes are less specific, whereas CC lasting less than 20 minutes are not associated with obstruction.

The patient with unexplained vomiting and symptoms of upper gastrointestinal stasis presents a diagnostic challenge;' sometimes, endoscopic, computed tomographic and contrast radiologic evaluations are unrewarding; thus, further specialised tests, such as transit measurements and recordings of upper gut motility, are undertaken.' These may detect the presence of disturbed gastrointestinal peristalsis as a result of a variety of neuromuscular diseases. ${ }^{2}$ The clinician, however, will often be concerned that the patient may have mechanical obstruction which was not detected on earlier anatomic investigations. The aim of this study is to assess whether jejunal manometry may provide features that are indicative of mechanical obstruction of the intestine. The ability to identify features of obstruction would be essential if manometric evaluation is to play a role in the clinical assessment of patients with unexplained symptoms such as vomiting and abdominal pain.

Address for correspondence: Michael Camilleri, MD, Associate Professor of Medicine, Division of Gastroenterology, Mayo Clinic, Rochester, MN 559(05. USA.

Accepted for publication 5 October 1988
The patterns of pressure activity generated in the proximal and distal small bowel of healthy volunteers during fasting and postprandially have been described in recent years, ${ }^{3-5}$ using a pneumohydraulic, low compliance perfusion system for manometry. It has become apparent that, in health, the ileum is the site of a unique, infrequent peristaltic wave that migrates rapidly through the region. ${ }^{\circ}$ In canine experiments, ${ }^{7}$ these contractile patterns, which migrate more rapidly than the migrating motor complex, are clearly associated with propulsion of liquid, and they have been proposed as an important force in the emptying of the ileum. Such phasic pressure activity has not been recorded in the proximal small bowel (duodenum or jejunum) of healthy individuals, or in a wide variety of gut dysmotilities caused by defects in intrinsic or extrinsic neural control, or by infiltrative disorders of the gut, such as scleroderma. ${ }^{2}$ Similar large amplitude waves of pressure, however, were detected in the distal small bowel in patients with 'functional' obstruction of the distal ileum after ileal pouch-anal anastomosis. ${ }^{x}$

In partial small bowel obstruction, Summers et al ${ }^{4}$ 
have reported postprandial clusters of contractions occurring once every two minutes, and lasting approximately one minute. Similar clusters of contractions are produced after acute obstruction in experimental models. ${ }^{111}$ Others ${ }^{12}$ have recently observed, however, such minute clustered contractions during the fasting period in patients with the irritable bowel syndrome, in healthy controls and in five of eight patients with ileal pouch-anal anastomosis after proctocolectomy. ${ }^{\circ}$ This study specifically assessed motility recordings from the human proximal small bowel for the presence of manometric features that would be consistent with mechanical bowel obstruction.

\section{Methods}

GASTROINTESTINAL MANOMETRY

The gastrointestinal manometric study ${ }^{13}$ was done after an overnight fast using a multiple-lumen perfusion tube introduced along a steerable catheter system. The perfusion assembly was positioned with the aid of fluoroscopy so that its tip was about 30 to 60 $\mathrm{cm}$ into the proximal jejunum. Two types of manometric assemblies were used, one with eight and the other with 12 perfusion catheters. Each of the eight or 12 catheters of the manometric tube was perfused with distilled water through a low compliance, pneumohydraulic pump (perfusion rate $0.1 \mathrm{ml} / \mathrm{min}$; perfusion pressure $14 \mathrm{psi}$ ) and attached to a strain gauge transducer (Gould Statham Instruments Inc, model P23, Hato Rey, Puerto Rico). One side opening was made in each catheter; three to six of these openings (which were $10 \mathrm{~cm}$ apart) were positioned in the proximal small bowel under fluoroscopic control. The remaining openings were fluoroscopically placed across the antroduodenal junction. Manometric recordings were transmitted to a paper chart recorder (Beckman Electronics Instruments, Schiller Park, IL) with a paper speed of $0.25 \mathrm{~mm} / \mathrm{s}$.

Recordings were undertaken for three hours in the

Table Manometric findings and diagnosis

\begin{tabular}{|c|c|c|c|c|c|c|c|}
\hline Case & Age & Sex & Fasting manometry & Fed manometry & Lap & $M O$ & Diagnosis \\
\hline \multicolumn{8}{|c|}{$C C<20 \min$} \\
\hline 1 & 69 & $\mathrm{~F}$ & Normal IMCs (2) & Early CC: 2 min periodicity & No & No & Idiopathic dysautonomia \\
\hline 2 & 47 & $\mathrm{~F}$ & Normal IMC & Early $\mathrm{CC}: 2 \mathrm{~min}$ periodicity & No & No & Irritable bowel syndrome \\
\hline 3 & 63 & F & Normal IMC & Early CC: $3 \mathrm{~min}$ periodicity & No & No & Irritable bowel syndrome \\
\hline \multicolumn{8}{|c|}{$C \mathrm{C}>30 \mathrm{~min}$} \\
\hline 4 & 76 & $\mathrm{~F}$ & IMC low amplitude & $\begin{array}{l}\text { Clusters } 1 \text { min duration, } 6 \mathrm{~min} \\
\text { periodicity }\end{array}$ & Yes & Yes & $\begin{array}{l}\text { Radiation stricture ileum on } \\
\text { barium } x \text {-ray }\end{array}$ \\
\hline 5 & 62 & $\mathrm{~F}$ & Normal IMC & $\begin{array}{l}\text { Clusters } 1 \text { min duration, } 3-4 \\
\text { periodicity }\end{array}$ & No & Yes & $\begin{array}{l}\text { Fixed ileal loops in pelvis on } \\
\text { barium } x \text {-ray }\end{array}$ \\
\hline 6 & 58 & $\mathbf{M}$ & Clusters & $\begin{array}{l}\text { Clusters } 1 \text { min duration; } 3 \text { min } \\
\text { periodicity }\end{array}$ & No & Yes & $\begin{array}{l}\text { Amyloidosis with infiltration in } \\
\text { jejunum on barium } x \text {-ray }\end{array}$ \\
\hline 7 & 43 & $\mathbf{M}$ & Clusters in phase II: normal IMC & $\begin{array}{l}\text { Clusters } 1 \text { min duration: } 2-3 \mathrm{~min} \\
\text { periodicity }\end{array}$ & No & Yes & Adhesions \\
\hline 8 & 63 & $\mathrm{~F}$ & Clusters in phase II & $\begin{array}{l}\text { Clusters } 1 \text { min duration: } 2-5 \mathrm{~min} \\
\text { periodicity }\end{array}$ & No & No & Probable CIIP \\
\hline 9 & 56 & $\mathbf{M}$ & Clusters in phase II: normal IMC & $\begin{array}{l}\text { Clusters } 1-2 \text { min duration: } 3-6 \mathrm{~min} \\
\text { periodicity }\end{array}$ & No & No & Probable CIIP \\
\hline 10 & 71 & $\mathbf{M}$ & $\begin{array}{l}\text { Normal IMCs (2) except distal } \\
\text { clustering }\end{array}$ & $\begin{array}{l}\text { Clusters } 1-2 \text { min duration; } 2-3 \mathrm{~min} \\
\text { periodicity }\end{array}$ & No & No & $\begin{array}{l}\text { Idiopathic sensory and autonomic } \\
\text { neuropathy }\end{array}$ \\
\hline \multicolumn{8}{|l|}{$P C$} \\
\hline 11 & 45 & $\mathrm{~F}$ & PC every $5-10 \mathrm{~min}$ & PC every $5-10 \mathrm{~min}$ & Yes & Yes & $\begin{array}{l}\text { Adhesions, radiation stricture in } \\
\text { distal ileum }\end{array}$ \\
\hline 12 & 50 & $\mathbf{F}$ & $\begin{array}{l}\text { PC every } 5-10 \mathrm{~min} \text { abnormal } \\
\text { propagation post-emesis IMC }\end{array}$ & $\begin{array}{l}\text { PC every } 5-10 \text { min; postemesis IMC } \\
\text { ends in } \mathrm{PC} \text { in distal lead }\end{array}$ & Yes & Yes & $\begin{array}{l}\text { Adhesions }+2^{\circ} \text { carcinomatous } \\
\text { stricture in distal ileum }\end{array}$ \\
\hline 13 & 44 & $\mathbf{M}$ & PC every $5-10 \mathrm{~min}$ & PC every minute & Yes & Yes & $1^{\circ}$ adenoCA jejunum \\
\hline \multicolumn{8}{|c|}{ Mixed $P C$ and $C C$} \\
\hline 14 & 37 & $\mathrm{~F}$ & $\begin{array}{l}\text { Duodenal clusters, jejunal PC } \\
\text { every } 5-10 \mathrm{~min}\end{array}$ & $\begin{array}{l}\text { Duodenal clusters ( } 1 \text { min duration) } \\
\text { and jejunal PC every } 2-5 \text { min }\end{array}$ & No & Yes & Adhesions \\
\hline 15 & 35 & $\mathbf{F}$ & PC every minute & $\begin{array}{l}\text { Irregular clusters duration } 5-10 \mathrm{~min} \text {, } \\
\text { periodicity } 10-20 \mathrm{~min}\end{array}$ & Yes & Yes & $\begin{array}{l}2^{\circ} \text { carcinomatous stricture in } \\
\text { transverse colon }\end{array}$ \\
\hline
\end{tabular}

Lap=laparotomy $\mathrm{MO}=$ mechanical obstruction: $\mathrm{PC}=$ simultaneous prolonged contractions; $\mathrm{CC}=$ postprandial clustered contractions: IMC = interdigestive migrating motor complex: $\mathrm{CIIP}=$ chronic idiopathic intestinal pseudo-obstruction. 
fasting state, and for two hours after ingestion of a mixed solid-liquid meal consisting of chicken, potato, butter, tapioca pudding and water $(24.3 \%$ protein, $20 \cdot 2 \%$ fat, $55 \cdot 5 \%$ carbohydrate, $190 \mathrm{ml}$ of distilled deionised water, and total caloric value of 511 $\mathrm{Kcal})$. Just before ingestion of the meal, the tube was advanced $3-5 \mathrm{~cm}$ to correct for change in its position because of postcibal accommodation of the stomach, and to retain adequate recording from the distal antrum.

REVIEW OF MANOMETRIC CHARTS

One observer reviewed 850 manometric records done between 1983 and 1987 on patients with unexplained nausea, vomiting, abdominal pain, or altered bowel movements. Among these patients, the main diagnostic categories were the following: 75 were known to suffer from diabetes mellitus; 25 had known neurological disorders (such as brain tumours, pandysautonomia, various neuropathies); 30 had a variety of infiltrative or myopathic disorders of the gut (such as scleroderma or amyloidosis); and 82 had postgastric surgery stasis syndromes. Sixty two patients fulfilled clinical and manometric criteria of chronic idiopathic intestinal pseudo-obstruction. ${ }^{14}$ Sixteen tracings were selected for the present study since they showed features suggestive of mechanical obstruction (see below). Thus, among the 850 manometric records, 290 were deemed to be abnormal. No other pathological abnormalities were identified in the remaining patients.

The aim of this manometric record review was to identify those that showed features that might be associated with mechanical obstruction distal to the pylorus. The duodenal and jejunal manometric features specifically sought were: first, prolonged ( $>20$ second duration) contractions (PC) occurring simultaneously in recordings at least $20 \mathrm{~cm}$ apart, and which might be expected to occur when several manometric catheters are sensing the same pressure in a dilated loop of bowel ('common cavity phenomenon'); and second postprandial clustered contractions (CC). Sixteen recordings were identified that showed either or both of these features.

The charts were assessed further for the following: (a) duration of manometric feature (PC or CC); (b) occurrence during fasting or postprandial periods; (c) duration of, and intervals between (periodicity) clustered contractions; and (d) 'background' motility of the proximal small bowel, apart from the $\mathrm{CC}$ and $\mathrm{PC}$.

REVIEW OF CLINICAL CASE RECORDS

Having identified and documented the manometric features in these 16 tracings, the clinical case records were reviewed to determine whether mechanical obstruction was shown in these patients. None of the remaining 834 patients had evidence of mechanical obstruction.

\section{Results}

MANOMETRIC CHARACTERISTICS

Among the 16 manometric charts with PC or CC, three were shown to have $\mathrm{CC}$ lasting less than 20 minutes, seven had CC lasting over 30 minutes, three had PC, and three, a mixed pattern of PC and CC.

The Table summarises the manometric findings in these three groups, as well as the effect on the fasting and postprandial pressure profiles in the proximal small bowel. Radiological studies or laparotomy showed mechanical obstruction in seven patients; two others had histories and clinical courses highly suggestive of adhesion obstruction but did not undergo laparotomy.

\section{CLUSTERED CONTRACTIONS LASTING LESS}

THAN 20 MINUTES

Three patients developed minute clustered contractions for less than 20 minutes in the early postprandial period. None were mechanically obstructed. The fasting and postprandial records were otherwise normal.

CLUSTERED CONTRACTIONS LASTING MORE

THAN 30 MINUTES

Among the seven patients with $\mathrm{CC}$ lasting more than 30 minutes, three had mechanical obstruction by small bowel $x$-ray (in two), and laparotomy (radiation stricture in the third). A fourth patient probably suffered recurrent subacute obstructions due to adhesions after major thoracoabdominal surgery carried out for accidental blunt trauma. The three other patients had no signs of mechanical obstruction. Five of these patients (including the three without mechanical obstruction) also had minute clusters during the fasting period. The duration of clusters was one to two minutes, and the periodicity varied between two and six minutes.

SIMULTANEOUS PROLONGED CONTRACTIONS Prolonged simultaneous contraction was associated with distal mechanical obstruction in three patients. All were proven to have obstruction at laparotomy and pathological examination of resected bowel (one primary carcinoma, one secondary carcinoma, one radiation stricture). Prolonged simultaneous contractions occurred during the fasting and postprandial periods in all patients in this group (Fig. 1). The amplitude of PC was greater than $20 \mathrm{mmHg}$ in all cases. 


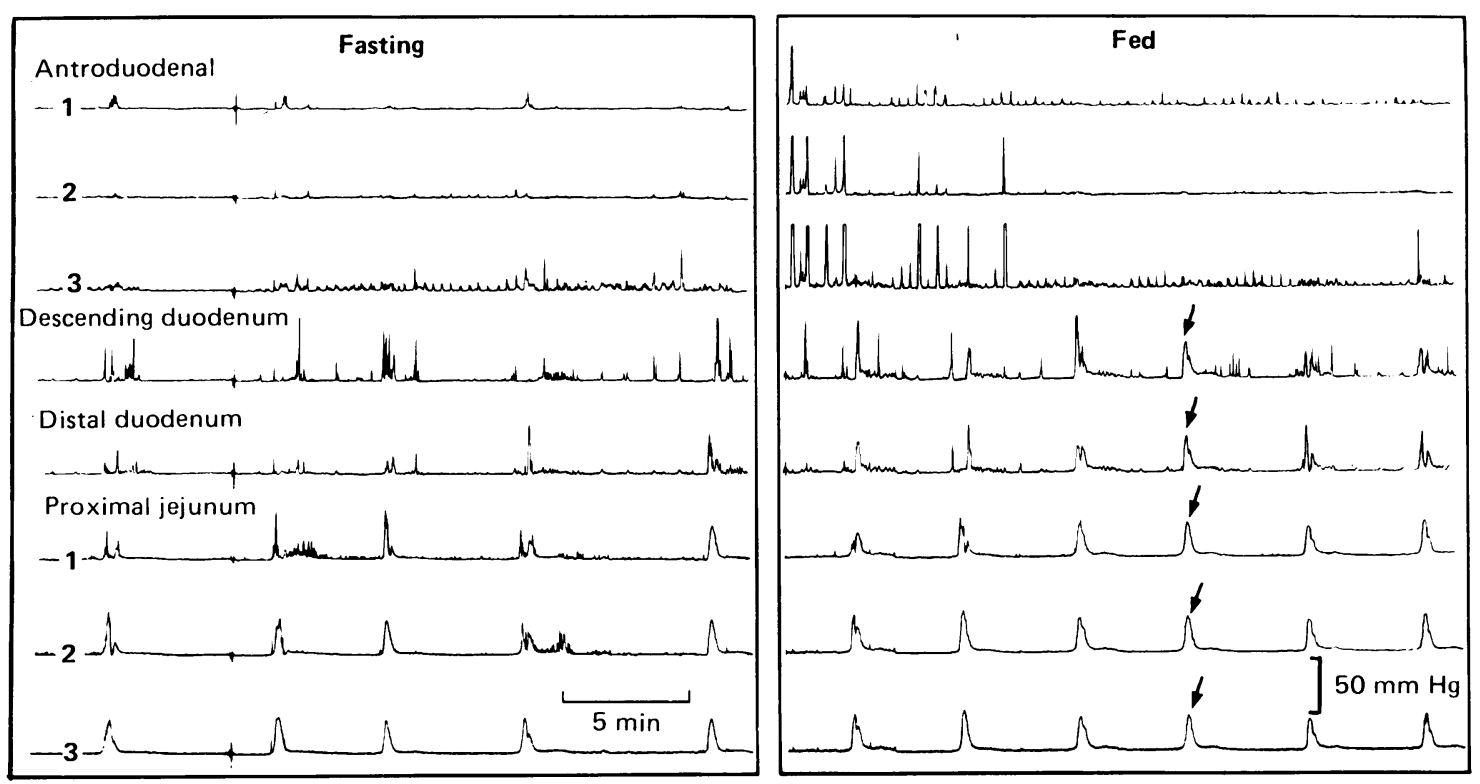

Fig. 1 Fasting and postprandial manometric record of patient 11: note the occurrence of simultaneous prolonged contractions (arrowed) in the small bowel proximal to a mechanical obstruction.
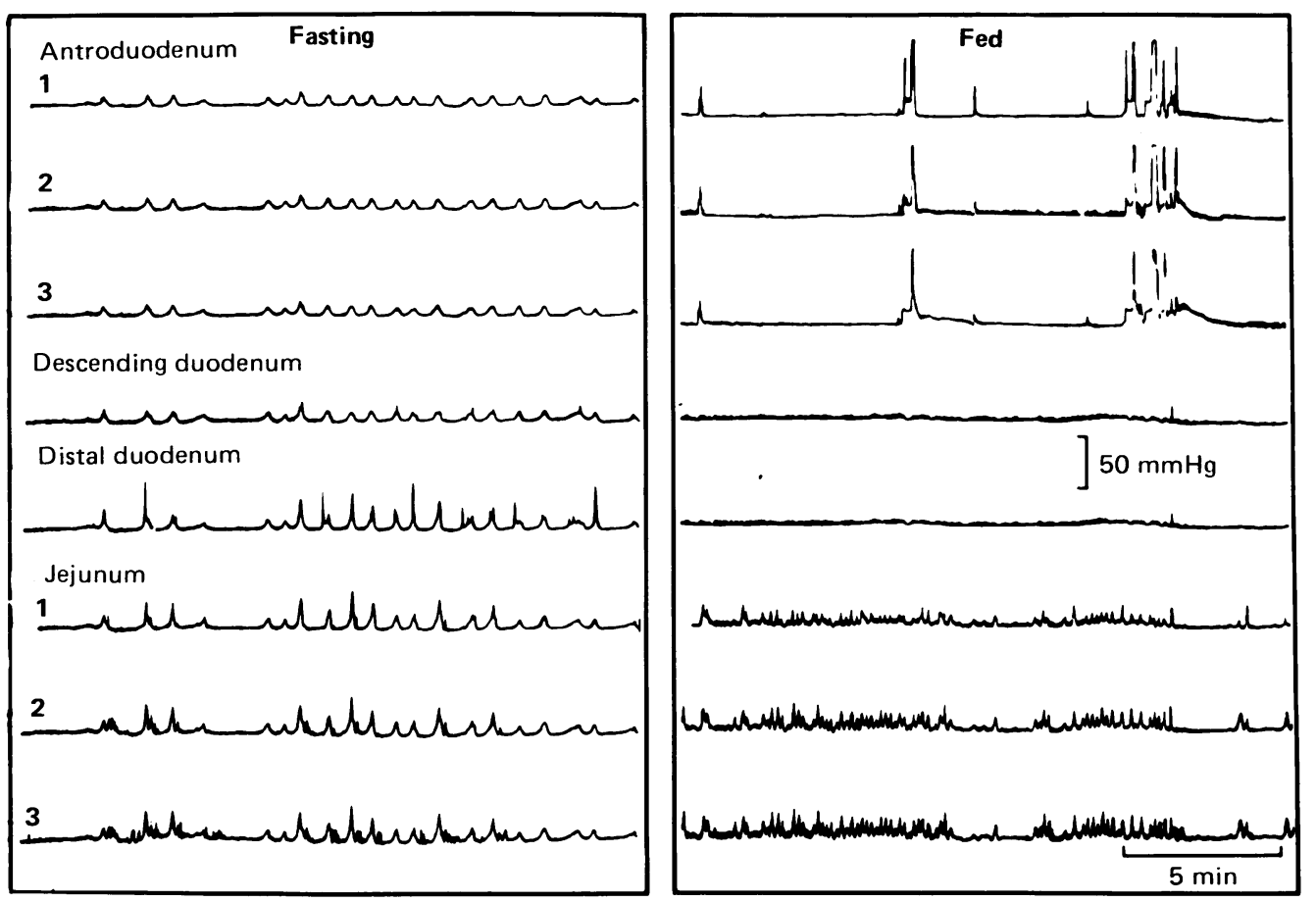

Fig. 2 Fasting and postprandial manometric records of patient 15: note the occurrence of prolonged contractions in the fasting tracing, and the development of simultaneous and unusually prolonged clusters of contractions in the small bowel proximal to a mechanical obstruction. 

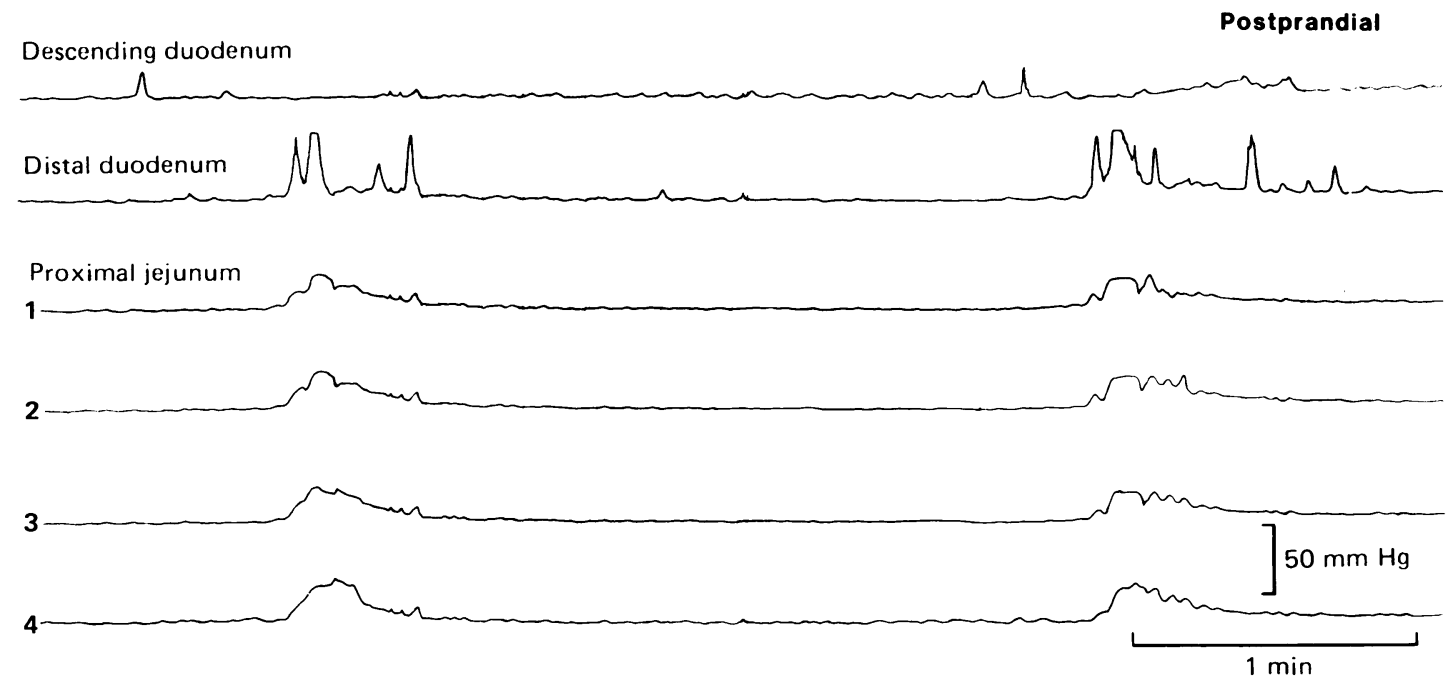

Fig. 3 Appearance of prolonged contractions with fast recording chart, demonstrating simultaneous contractions at different levels of the upper small bowel.

MIXED PATTERN: PC AND CC

Three patients manifested a mixed manometric pattern of PC and CC. In one patient with a carcinomatous stricture, there were PC during the fasting period, and clustered contractions postprandially (Fig. 2). The latter were of variable duration and periodicity but appeared to occur simultaneously or were rapidly propagated in the
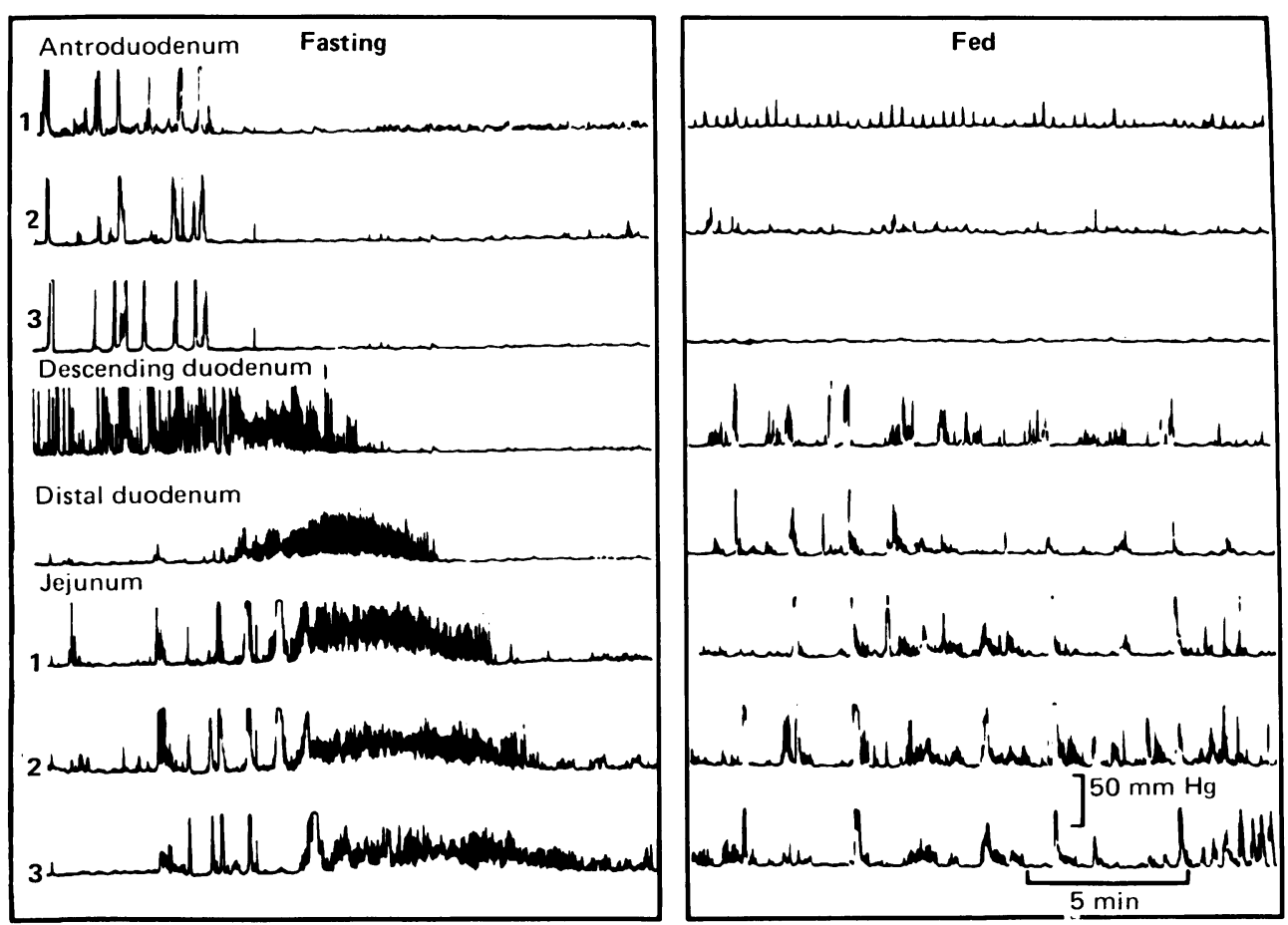

Fig. 4 Appearance of prolonged contractions during phase III of interdigestive migrating motor complex and interspersed among postprandial clustered contractions. 
small bowel segments evaluated manometrically. Recordings obtained with accelerated recorder speed show (Fig. 3) that PC were recorded simultaneously at different levels of the proximal small bowel of such patients.

A second patient had a history of six previous abdominal operations, and more than 10 episodes of subacute intestinal obstruction during the two years before evaluation by manometry. She was assumed to have obstruction caused by adhesions, although small bowel $x$-ray was non-contributory. Her manometry showed a mixed pattern of clustered contractions in the duodenum, and PC in the jejunum. These different contractile patterns appeared to be coordinated and had the same periodicity. A third patient with a radiation stricture showed PC during phase III of the interdigestive migrating motor complex (which was otherwise normal), and PC among postprandial clustered contractions (Fig. 4).

\section{Discussion}

This study has extended previous observation ${ }^{y-11}$ on the manometric features of the proximal small bowel in mechanical obstruction of the intestinal tract. Apart from the clustered contractions," usually of one to two minutes duration and variable periodicity, this report documents, for the first time, the occurrence of prolonged ( $>20$ seconds), contractions occurring simultaneously in the human duodenum and proximal jejunum. Such contractions have not been reported previously in health, or in disease states in the proximal small bowel. This manometric picture in the proximal small bowel is reminiscent of the simultaneous prolonged contractions seen at different levels of the oesophagus in achalasia, and likely represents recording of intraluminal pressure in a distended common cavity.

Pathophysiologically, both the oesophagus in achalasia, and the small bowel proximal to an obstruction adapt their motility patterns to try to overcome the functional or mechanical obstruction. Indeed, the ileum proximal to an ileal pouch-anal anastomosis $^{x}$ similarly generates high amplitude waves proximal to the intended 'functional obstruction' produced by the surgically created pouch. Whereas the simultaneous contractions in the achalasic oesophagus are attributed to pressure activity that engages the whole muscle at once in a 'common cavity', such a mechanism is less likely to be responsible for the prolonged contractions in the proximal jejunum when a mechanical obstruction is documented in the distal ileum (patients 11, 12, and 16 in this study) and transverse colon (patient 15). In the latter cases it is conceivable that the intrinsic circuitry that controls gut motility sets up a stereotyped motor response ${ }^{15}$ that is characterised by either prolonged contractions or discrete clusters of contractions that, are separated by periods of motor quiescence. It is conceivable that the simultaneous prolonged phasic pressure activity represents a contraction that is occurring simultaneously at a number of different sites possibly as a result of spasm of a long length of bowel.

The characteristics (duration, amplitude) of the individual PC observed in patients with mechanical obstruction are similar to those observed in the normal mammalian ileum ${ }^{\circ 7}$ however, the frequency of PC is markedly increased in patients with partial bowel obstruction. The proven propulsive effect ${ }^{7 / 6}$ of these contractions in the distal ileum of experimental dogs suggests they may be an adaptive response of the proximal intestine to set up more potent propulsive forces in an attempt to overcome distal obstruction.

The demonstration of the ability of the mammalian intestine to generate prolonged contractions proximal to an obstruction is certainly not new. During the earlier half of this century, several workers had observed, in experimental models, the rise in intraluminal pressure in the intestine proximal to an obstruction. The resting pressure or 'tone' was $6-8 \mathrm{~cm}$, rising to $30-60 \mathrm{~cm}$ water during maximum contractions in experimental obstruction with an occluding balloon. ${ }^{17}$ Others found pressures of 4-10 $\mathrm{cm}$ water,${ }^{18}$ and an average of $26.8 \mathrm{~cm}$ water ${ }^{19}$ in simple obstruction of the lower ileum. The duration of these contractions was not specifically recorded in the earlier literature. More recently, in studies in the cat with distal small bowel obstruction,,$^{210}$ there were long periods of inactivity alternating with short bursts of spontaneous bowel activity reaching up to 20 $\mathrm{mmHg}$. Moreover, the pronounced contractions in the left colon of the monkey proximal to an experimentally induced obstruction appeared to occur simultaneously with those in the terminal ileum and ascending colon, and were observed every three minutes in experiments with total obstruction of the colon..$^{21}$

The combined manometric pattern of clustered contractions proximally associated with PC more distally was observed in three patients with mechanical obstruction. A similar phenomenon has been observed in the proximal small bowel of dogs after previous Roux-en-Y gastrectomy or Billroth I gastrectomy. In these canine models, however, such contractions occur very infrequently (mean interval $6 \cdot 1$ hours) ${ }^{16}$

The other manometric pattern of postprandial clustered contractions is not as indicative of mechanical obstruction. Thus, only four of seven 
patients with $\mathrm{CC}$ lasting more than 30 minutes had mechanical obstruction, and none of three patients in whom CC lasted less than 20 minutes were obstructed. Thus, our observations on CC are in agreement with those previously published by Summers et al "' on patients with mechanical obstruction and intestinal pseudo-obstruction. The rhythmic clusters observed in this study had more variable periodicity than in the previous study," and the duration of each cluster of contractions was also more variable. The significance of this variation is unclear. As the rhythmic clusters of pressure activity recorded in patients with the irritable bowel syndrome ${ }^{12}$ or after ileal pouch anal anastomosis ${ }^{k}$ were only present in the interdigestive or fasting period, their occurrence in the postprandial period for more than 30 minutes should still alert the investigator to the possibility of mechanical bowel obstruction.

In the manometric evaluation of patients with symptoms of upper gut stasis, such as vomiting, and abdominal pain," the recognition of patterns suggestive of mechanical obstruction becomes important. This is particularly so when previous radiological evaluation has failed to reveal the obstruction or when the patient has an underlying disease (such as amyloidosis) or has undergone previous treatment (such as radiotherapy) that may produce a radiologic picture of dilated small bowel loops from either pseudo-obstruction or strictures. ${ }^{1322-25}$ Clearly the usual diagnostic strategies of contrast radiology and endoscopy remain the sheet anchors in evaluation of patients with suspected mechanical obstruction. When these tests do not provide unequivocal evidence for obstruction, manometry is often done to search for features of disordered gut motility. This study has provided insight on the relative sensitivity of duodenal and jejunal PC as indicators of obstruction. It has confirmed previous observations ${ }^{10}$ that postprandial clustered contractions may occur in the mechanically obstructed small bowel of man. The sensitivity and specificity of these manometric features deserve further evaluation in a prospective study. In particular, it is necessary to estimate the false positive rate of the manometric test, and at present, the data from this retrospective study suggest that manometry is a useful adjunct to the diagnostic armamentarium in assessing patients with suspected mechanical obstruction, but it should not be used alone in the assessment of such patients.

This study was reported in part at the meeting of the American Gastroenterology Association, New Orleans, May 1988 and appeared in abstract form in Gastroenterology 1988; 94: A57. I would like to thank Drs J-R Malagelada and S F Phillips for helpful discussions, Mr Craig B Reeves and Mr Duane B Burton for supervision of the motility recordings and Ms Linda Rasmussen and Ms Linda Bakken for typing and preparing this manuscript.

\section{References}

1 Malagelada J-R, Camilleri M. Unexplained vomiting: a diagnostic challenge. Ann Intern Med 1984; 101: 211-8.

2 Malagelada J-R. Camilleri M. Stanghellini V. Manometric diagnosis of gastrointestinal motility disorders. New York: Thieme Inc. 1986.

3 Rees WDW, Malagelada J-R, Miller LJ, Go VLW. Human interdigestive and postprandial gastrointestinal motor and gastrointestinal hormone patterns. Dig Dis Sci 1982; 27: 321-9.

4 Kerlin P. Phillips SF. Variability of motility of the ileum and jejunum in healthy humans. Gastroenterology 1982; 82: 694-700.

5 Kerlin P. Zinsmeister A. Phillips SF. Motor responses to food of the ilcum. proximal colon. and distal colon of healthy humans. Gastroenterology 1983; 84: 7620-770).

6 Quigley EMM, Borody TJ, Phillips SF, Weinbeck M. Tucker RL. Haddad A. Motility of the terminal ileum and ileocecal sphincter in healthy humans. Gastroenterology 1984; 87: 857-66.

7 Kruis W. Azpiroz F. Phillips SF. Contractile patterns and transit of fluid in canine terminal ilcum. Am J Physiol 1985; 249: 264-70.

8 Stryker SJ, Borody TJ, Phillips SF, Kelly KA, Dozois RR, Beart RW Jr. Motility of the small bowel after proctocolectomy and ileal pouch-anal anastomosis. Ann Surg 1985; 301: 351-6.

9 Summers RW. Anuras S, Green J. Jejunal manometry patterns in health, partial intestinal obstruction, and pseudo-obstruction. Gastroenterology 1983; 85: 1290300 .

10 Summers RW, Yanda R, Prehoda M, Flatt A. Acute intestinal obstruction: an electromyographic study in dogs. Gastroenterology 1983; 85: 1301-6.

11 Dahlgren S, Thoren L. Intestinal motility in low small bowel obstruction. Acta Chir Scand 1967; 133: 417-21.

12 Kellow JG, Phillips SF. Altered small bowel motility in irritable bowel syndrome is correlated with symptoms. Gastroenterology 1987; 92: 1885-93.

13 Camilleri M, Malagelada J-R, Stanghellini V, Fealey RD. Sheps SA. Gastrointestinal motility disturbances in patients with orthostatic hypotension. Gastroenterology 1985; 88: 1852-9.

14 Stanghellini V. Camilleri M, Malagelada J-R. Chronic idiopathic intestinal pseudo-obstruction: clinical and intestinal manometric findings. Gut 1987; 28: 5-12.

15 Wood JD. Enteric neurophysiology. Am J Physiol 1986; 247: 585-98.

16 Ehrlein H-J, Schemann M, Siegle M-L. Motor patterns of small intestine determined by closely spaces extraluminal transducers and videofluoroscopy. Am J Physiol 1987; 253: 259-67.

17 Owings JC, McIntosh CA, Stone HS, Weinburg JA. Intraintestinal pressure in obstruction. Arch Surg 1928; 17: 507-20.

18 Sperling L, Paine JR, Wangensteen $\mathrm{OH}$. Intra-enteric 
pressure in obstruction. Proc Soc Exp Biol Med 1935; 32: $1504-5$.

19 Antoncic RF, Lawson $\mathrm{H}$. The muscular activity of the small intestine in the dog, during acute obstruction. Ann Surg 1941; 114: 415-23.

20 Ohman U. Studies on small intestinal obstruction I. Intraluminal pressure in experimental low small bowel obstruction in the cat. Acta Chir Scand 1975; 141: 413-6.

21 Fraser I. Motility charges associated with large bowel obstruction and its surgical relief. Ann R Coll Surg Engl 1984; 66: 321-6.

22 Malagelada J-R, Stanghellini V. Manometric evaluation of functional upper gut symptoms. Gastroenterology 1985: 88: $1223-31$.

23 Ikeda S-I. Makishita H. Oguchi K, Yanagisawa N, Nagata T. Gastrointestinal amyloid deposition in familial amyloid polyncuropathy. Neurology (NY) 1982; 32: 1364-8.

24 Conklin JL, Anuras S. Radiation induced recurrent intestinal pseudo-obstruction. Am J Gastroenterol 1981; 75: 440-4.

25 Novak JM. Collins JT, Donowitz M, Farman J, Sheahan DG. Spiro HM. Effects of radiation on the human gastrointestinal tract. J Clin Gastroenterol 1979; 1: 9-39. 